\title{
Escrituras del ambiente, el paisaje y el territorio: ecocrítica y estudios culturales en América del Sur
}

\author{
WRITINGS OF ENVIRONMENT, LANDSCAPE AND TERRITORY: ECOCRITICISM AND \\ CULTURAL STUDIES IN SOUTH AMERICA
}

\section{ESCRITOS DE MEIO AMBIENTE, PAISAGEM E TERRITÓRIO: ECOCRÍTICA E ESTUDOS CULTURAIS NA AMÉRICA DO SUL}

\author{
Allison Mackey *1 \\ Victoria Lembo ** \\ Mauricio Cheguhem *** \\ Sofia Rosa Rivero **** \\ amackey@fhuce.edu.uy \\ victorialembo@gmail.com \\ mauriche8@gmail.com \\ srosa2@uc.cl
}

\section{Introducción}

Este número de Tekoporá: revista latinoamericana de humanidades ambientales y estudios territoriales presenta una selección diversa de aportes que contribuyen a la comprensión de las variadas problemáticas que emergen de las representaciones de la relación entre la cultura y la naturaleza dentro de contextos ambientales específicos de Latinoamérica. El auge de las humanidades ambientales en los últimos años coincide con el giro hacia el "Antropoceno", término propuesto por el químico Paul J. Crutzen y el biólogo Eugene F. Stoermer en el año 2000 para describir la época en la que el cambio climático y otros efectos antropogénicos posicionan a la humanidad como fuerza geológica, capaz de transformar el sistema planetario y dejar su marca escrita en los estratos geológicos de la tierra, algo que es evidente en diversas escalas. Esta nueva comprensión de lo humano en relación con su planeta ha sido catalizadora de preguntas vitales sobre el posicionamiento del sujeto en el discurso de las especies, la historia, el medio ambiente, la política, y la cultura.

La ecocrítica, afincada en los estudios literarios y culturales, propuso en sus inicios la necesidad de practicar la "fertilización cruzada" (Glotfelty, 1996, p. xix) entre disciplinas para garantizar un enfoque ecocéntrico de los problemas ambientales. Por ejemplo, por lo menos desde que la bióloga marina y

\footnotetext{
1 * Facultad de Humanidades y Ciencias de la Educación de la Universidad de la República

**Centro Universitario Región Este de la Universidad de la República

****Universidad de Salamanca

*****Pontificia Universidad Católica de Chile
} 
conservacionista estadounidense Rachel Carson decidió comenzar su libro documentando los efectos ambientales adversos causados por el uso indiscriminado de plaguicidas, Silent Spring (1962), con un cuento, "A Fable for Tomorrow", ha quedado claro el rol potencialmente transformador de la narrativa y de la ficción en la comunicación de las ciencias. Un número creciente de investigaciones interdisciplinarias demuestra que la ecocrítica se cultiva a través de lecturas indisciplinadas sobre la relación entre la naturaleza y la cultura para la construcción de conocimientos situados y críticos. En su antología pionera editado con Harold Fromm, The Ecocriticism Reader (1996) la crítica norteamericana Cheryl Glotfelty definió el campo de la ecocrítica como una propuesta centrada en la tierra y en los territorios, desde la cual se exploran y analizan los estudios literarios y culturales:

La ecocrítica es el estudio de las relaciones entre literatura y el entorno físico. Así como la crítica feminista examina el lenguaje y la literatura desde una perspectiva de conciencia de género y la crítica marxista se ocupa del modo de producción y de clase económica en su lectura de los textos, la ecocrítica toma un enfoque centrado en la tierra para sus estudios literarios. (p. xiii)

Como señala la Carta Mundial de la Naturaleza adoptada por la Asamblea General de las Naciones Unidas en 1982, la "civilización tiene sus raíces en la naturaleza, que moldeó la cultura humana e influyó en todas las obras artísticas y científicas". En pocas palabras, la ecocrítica busca entender no sólo las diversas maneras en que la actividad humana (histórica, contemporánea e imaginada) da forma al mundo que nos rodea, sino que también indaga en la forma en que los procesos "naturales" de la tierra dan forma a las vidas sociales, culturales y económicas de las personas, reflejando lo que Karen Barad (2007) llama la "intra-acción" y "agencialidades enredadas" que hay entre intérprete humano y la textualidad de lo material. Lawrence Buell (2005) observa en el siglo XXI la aparición de una "segunda ola" de ecocrítica que desafía los parámetros centrados en gran medida en tradiciones críticas de la anglósfera (desde academias británicas y norteamericanas), impulsando la aparición de lecturas ecocríticas de literaturas y culturas poscoloniales, y estimulando el compromiso con temáticas ambientales por parte de artistas, escritores, académicos y activistas del sur global.

Dadas las dificultades que son inherentes al trasladar un "campo disciplinario emergente angloamericano a contextos latinoamericanos", como señaló Gisela Heffes en "Para una ecocrìtica latinoamericana” (2014, p. 21), este número de Tekoporá se compromete a explorar la manera en que "se conjugan, dentro del campo de esta disciplina emergente, preocupaciones medioambientales con las expresiones textuales, visuales y artísticas provenientes de América Latina" (p. 11). Los artículos en este número plantean, más o menos explícitamente, el problema de "cómo [las] representaciones latinoamericanas redefinen y reconfiguran aquellos conceptos formulados, originalmente, por la ecocrítica, apostando y proponiendo nuevas formas de lectura, conceptualización, efectos y marcas distintivas" (p. 21). A siete años del proyecto seminal de Heffes, donde intentó "delimitar algunos de los contornos que la disciplina de la ecocrítica-y 
todas sus constelaciones-ha ido tomando en los últimos años" (p.32), nos preguntamos: ¿dónde se inserta este número de Tekoporá dentro de estas conversaciones?

Los artículos aquí reunidos muestran una gran diversidad de perspectivas y acercamientos teóricos, metodológicos, y disciplinarios, presentando una multiplicidad de formas de abordar la temática a través de lecturas desde una variedad de géneros: poesía, novelas, cine, relatos de viaje, arte visual, arquitectura, instalaciones artísticas, relatos personales, textos históricos y contemporáneos. Los intereses de los/as autores/as reflejan también una gran diversidad geográfica: desde la región donde nace la revista en Maldonado, Uruguay, se diversifican las perspectivas para abarcar el resto de Hispanoamérica. En 2010 los editores del volumen Ecocríticas: Literatura y medio ambiente notaron que "el 95\% de la literatura teórica y crítica de este movimiento están en inglés" (Flys, Marrero y Barella, p. 23). Por lo tanto, cabe señalar que los estudios ecocríticos aplicados a la producción cultural latinoamericana que aparecen en este número de Tekoporá representan-desde la perspectiva del sur y en español-una contribución oportuna e importante al campo de la ecocritica. El llamado original invitando contribuciones al número fue generalizado en lugar de específico, por lo que las temáticas y diálogos teóricos recurrentes-así como las lagunas y omisiones del número-son en gran parte aleatorias. Tendimos una red amplia y esto es lo que capturamos, por lo cual no pretende ser un número exhaustivo.

Tal como señala el título del número, los artículos responden a tres coordenadas fundamentales para los estudios ecocríticos en particular y ambientales en general. Nos referimos aquí al tríptico "territorio, paisaje y ambiente". Cada uno de ellos no representa sencillamente un enfoque o sistema de organización, sino que revela la epistemología que aquí intentamos anunciar. En primer lugar, el territorio describe el espacio como un otro, un espacio material cuya entidad es independiente de la mirada y tiene ante sí, su propia entidad ontológica. Por otra parte, tal como fue concebido por el "giro espacial" que emerge en el siglo XX, el paisaje no es un ente alejado de nosotros, sino que implica necesariamente la dimensión del sujeto como fenómeno estético. Resulta evidente, en este sentido, que no existiría el paisaje sin la mirada o la percepción, es decir, sin el sujeto. Como reflexiona el padre de los poetas modernos, Charles Baudelaire: "Si ese conjunto de árboles, de montañas, de aguas y de casas, que llamamos un paisaje, es bello, no es por sí mismo, sino por mí, por mi gracia propia, por la idea o el sentimiento que le dedico" (p. 273). Por último, no se trata de reproducir los binarismos que han estructurado la cultura moderna desde Descartes hasta nuestros días, sino que el verdadero desafío del pensamiento ecológico consiste en disolver los dualismos ontológicos objeto/sujeto y territorio/paisaje. Podemos decir entonces que aquí entra en escena la síntesis de este movimiento: ambiente.

El ambiente engloba sujeto y objeto como una comunidad de agentes en ambas direcciones, sorteando la histórica división entre sujeto y objeto, por un lado, y de paisaje y territorio por el otro, proporcionando una nueva dimensión acerca de la interrelación de conciencias más que humanas. En este contexto queroíemos señalar otro aspecto del título de la revista: los orígenes guaraníes del concepto del "buen vivir" - teko porã_como una noción filosófica, política, social y 
espiritual sobre la buena forma de caminar sobre esta tierra, algo que se expresa cuando se vive en equilibrio, respeto y armonía con el entorno. Al mismo tiempo, es importante recordar la palabra emparentada, tekoha, que significa el lugar del modo de ser del guaraní, o, el lugar donde somos lo que somos. En la cosmología guaraní, sin tekoha no hay teko porã, y tal como lo explica Graciela Evia, en contraste con "la sociedad occidental" donde el "yo" es el "ser humano con límites corporales", en la cosmovisión guaraní un individuo "sólo puede reconocerse como persona inserta en un ambiente natural". En otras palabras, el Yo y el entorno son "una unidad indivisible" (2006).

Los conceptos que estamos tomando como coordenadas referenciales nos advierten sobre nuestros límites para abordar discursos heterodoxas frente a la tradición humanista, ya que términos como "Antropoceno" y "Humanidades Ambientales" no solo provienen de marcos euro-norteamericanos, sino que también posicionan a la humanidad como eje central en su misma enunciación. Al mismo tiempo que asumimos los riesgos de cierto antropocentrismo inevitable ¿cómo podemos hacer una relectura de nuestra relación con las otras especies y la tierra desde las humanidades? Elizabeth DeLoughrey nos recuerda que "[un] modelo antropocéntrico de pensamiento de especies tiende a pasar por alto las formas en que los seres humanos están constituidos, incluso en nuestro ADN, como criaturas interespecies" (2015, p. 362). En esta línea, una de las corrientes que atraviesa los artículos en este número refleja lo que se ha denominado el "giro material" en los estudios críticos. Varios de los contribuyentes se comprometen con la ecocrítica material, ejemplificado en pensadores como Bruno Latour y Donna Haraway, por ejemplo. Según Serenella Iovino y Serpil Oppermann en la introducción a su libro Material Ecocriticism (2014):

La ecocrítica material, en este amplio marco, es el estudio del modo en que las formas materiales (cuerpos, cosas, elementos, sustancias tóxicas, sustancias químicas, materia orgánica e inorgánica, paisajes y entidades biológicas) actúan en forma intransigente entre sí y con la dimensión humana, produciendo configuraciones de significados y discursos que podemos interpretar como relatos [stories] (p 7).

Para intentar alejarse de la perspectiva del humano como sujeto de una relación donde las formas de vida no-humanas (animales y otras) son objetos para ser subsumidas, el giro poshumano en las humanidades propone que el ser humano es simplemente otra relata entre muchos.

Desde dentro de las humanidades también se ha señalado el fracaso del Antropoceno como concepto para explicar adecuadamente las relaciones de poder y desigualdad planetaria que nos han conducido hasta la crisis actual. Por cierto, no todos los humanos en todos los rincones del mundo estamos igualmente implicados bajo el signo de la humanidad y es importante cuestionar, como lo hace Rosi Braidotti, "¿quién es este 'nosotros' cuya humanidad está en juego?" (2019, p. 86). De hecho, hay toda una panoplia de términos alternativos que se han propuesto para describir el momento geológico que estamos atravesando en el planeta (desde "Capitaloceno", que intenta resaltar las fuerzas perjudiciales del capitalismo, a "Plantaciónoceno", que enfatiza el papel del colonialismo, el sistema 
de plantaciones y el trabajo esclavo, a términos como "Androceno" o "Faloceno" para señalizar las opresiones entrelazadas de género y especie). Pero, en lugar de abandonar el término totalmente, críticas como Heather Davis y Zoe Todd, miembros del Anthropocene Working Group, ven cierta productividad en el hecho de que "el Antropoceno se traiciona a sí mismo en su nombre," ya que "en su reafirmación de universalidad, implícitamente se alinea con la época colonial" (2017, p.763). Para las autoras, solamente si se hacen explícitas las relaciones entre el Antropoceno y el colonialismo podemos comprender la actual crisis ecológica más allá de su encuadre eurocéntrico, y de esa forma contribuir a descolonizar el Antropoceno. Davis y Todd se alinean con la fecha del "Orbis Spike" propuesta por los geólogos británicos Simon Lewis y Mark Maslin en su artículo en la revista Nature (2015). ${ }^{2}$ Lewis y Maslin toman el "descubrimiento" europeo de las Américas y el genocidio contra sus habitantes originales como umbral de la nueva época geológica y, por tanto, vinculan explícitamente el Antropoceno con los inicios de la colonización de las Américas.

La controversia geológica sobre el inicio del Antropoceno reafirma la necesidad de pensar trayectorias más amplias, pues establecer las continuidades entre colonialismo y Antropoceno lo afirma como un "proyecto crítico que comprende que las lógicas ecocidas que ahora gobiernan nuestro mundo no son inevitables o [debido a una] 'naturaleza humana', sino que son el resultado de una serie de decisiones que tienen su origen y reverberación en la colonización", que es "una ideología específica definida por lógicas protocapitalistas basadas en la extracción y acumulación a través del despojo" (Davis y Todd, p. 763). Por lo tanto, esta (re)definición de comienzos (que a la vez son finales) de injusticias ambientales que se experimentan como un dèja vu colonial (Whyte 2016), nos urge a reconocer o rescatar cosmologías y epistemologías que han sido desplazadas y silenciadas por lógicas de dominación para poder atender a la urgencia de la situación ecológica contemporánea e imaginar futuros alternativos.

Becky Boling (2006) identifica una transición en la forma en que los/as escritores/as conciben el mundo "natural" en las letras latinoamericanas-desde las primeras manifestaciones en la escritura utópica de la promesa del "nuevo mundo," pasando por el dualismo civilización/barbarie de Sarmiento, a textos que ensalzan la urbanización y el desarrollo de los espacios-el tropo de la naturaleza ha sufrido varias permutaciones que dicen mucho sobre los contextos ideológicos

\footnotetext{
${ }^{2}$ El debate geológico gira en torno a definir la fecha de inicio del Antropoceno, y por tanto, la marca geológica en los estratos: hasta que apareció el artículo de Lewis y Maslin hubo gran acuerdo en que los marcadores geológicos coinciden con una fecha de inicio para el Antropoceno en la década de 1950 - el comienzo de lo que se llama "la gran aceleración" (Steffen et al 2015) - que incluye los niveles de dióxido de carbono, las extinciones masivas y el uso generalizado de productos petroquímicos, incluido el plástico, y el "plutonio que queda de la radiactividad resultante de la detonación de bombas atómicas" (Davis and Todd, p.763). En cambio, la hipótesis "Orbis Spike" de Lewis y Maslin propone como marca la disminución del dióxido de carbono atmosférico registrada alrededor de 1610 a raíz del genocidio de los pueblos indígenas y el proceso de homogenización de especies cuando una cantidad de plantas y animales se intercambiaron entre Europa y las Américas, "reformulando drásticamente los ecosistemas de ambas masas terrestres, evidencia de lo cual se puede encontrar en la capa geológica a través de los tipos de biomasa acumulados allí" (p. 766).
} 
de los escritores y su conceptualización del lugar de los humanos en el esquema de las cosas. Donde las narrativas de finales del siglo XX marcan un alejamiento de las conceptualizaciones anteriores de la naturaleza en el contexto de la urgencia de la ecología y la globalización, la literatura de orientación ecológica en el siglo XXI parece expresar una urgencia ética relacionada a repensar el lugar del humano dentro de la naturaleza, descentralizando el Anthropos y desestabilizando la perspectiva humana desde la cual entender conceptos como territorio, paisaje y ambiente. La pluralidad de perspectivas representadas en este número recupera puntos de vista que han sido marginalizados, desde cosmologías indígenas a epistemologías feministas y queer, señalando la importancia de concebir al ambientalismo interseccional en el contexto de las humanidades ambientales en América Latina.

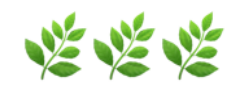

Los artículos que integran la primera sección de este número de Tekoporá analizan la conurbación Maldonado-Punta del Este, hogar de la revista, partiendo de la idea del espacio no como un receptáculo vacío e inerte, objetivo y neutral, sino como un producto social. En este sentido, el espacio es entendido como el resultado de las prácticas sociales y a su vez como parte de ellas, dando cuenta de lo que Lefebvre (2013) llamó la "tríada conceptual" (p.92) compuesta por las prácticas espaciales, las representaciones del espacio y los espacios de representación. Los y las autoras dialogan y discuten sobre las tensiones y conflictos que se producen entre el espacio concebido-es decir, aquel espacio diseñado y propuesto por los expertos, los científicos y los planificadores-y el espacio vivido y percibido, logrando de esta manera incorporar al análisis el diálogo entre lo material, lo físico, lo mental y lo social.

Los/as autores/as reconocen a la zona (especialmente a la ciudad de Punta del Este) como uno de los puntos turísticos históricamente más importantes de América del Sur. Asimismo, evidencian las vertiginosas transformaciones ocurridas en las últimas décadas debido al aumento del turismo residencial que ha afectado el ambiente y el paisaje, la relación de la población con su entorno, así como los vínculos sociales entablados por los propios pobladores (algunos expulsados de lugares de gran interés turístico y otros atraídos por la búsqueda de nuevas oportunidades laborales). Por otra parte, constatan que esta compleja trama de desigualdad de inclusiones y exclusiones es invisibilizada por un relato dominante que se presenta como un producto acabado clarificador y coherente, que se aleja del conflicto y de las relaciones de poder que se juegan en los espacios, así como de la complejidad de la realidad social.

Con su artículo "En la rompiente: subjetividades arrancadas de la costa, subjetividades arrastradas a la costa. Conflictos socioterritoriales y socioambientales en torno al principal balneario uruguayo", Eliane Gerber indaga en las construcciones subjetivas de quienes habitan este espacio, prestando atención al concepto de ambiente y al de memoria ambiental. Deja constancia de la dinámica poblacional $(\mathrm{y}$ con ello de los conflictos socioterritoriales $\mathrm{y}$ 
socioambientales) producida por lo que identifica como uno de los impactos más fuertes del turismo residencial: la transformación de la tierra en suelo, entendiendo el suelo como una mercancía y objeto de consumo hasta su total agotamiento. Hace especial hincapié en los dolores subjetivos provocados por la transformación de los espacios y destaca la imposibilidad de los habitantes de visualizar las causas reales del conflicto y de responsabilizar a los migrantes de bajos recursos de los problemas asociados a la "degradación del paraíso".

Por su parte, Federico Sequeira en "Ciudades turísticas latinoamericanas, relatos posibles desde las artes visuales. El caso de Punta del Este" también reflexiona sobre la relación de los pobladores y la de éstos con el ambiente y sobre las vertiginosas transformaciones que ha provocado el creciente fenómeno turístico. El análisis se enfoca en las artes visuales como representaciones y también como dispositivos de memoria, a través de los cuales se puede interpretar un sentido posible sobre determinado lugar (Giunta, 2014). Se pregunta si se puede identificar momentos, idealizaciones o tensiones propias de las ciudades, a través de las obras artísticas que se producen por y para ellas. Para abordar estas cuestiones, propone un recorrido sobre diferentes obras clasificándolas en tres categorías: artes visuales consagradas; obras de arte en emprendimientos hoteleros e inmobiliarios, y obras en clave crítica. Entre otras cuestiones, el autor concluye que las artes visuales, más allá de su valor canónico, de mercado o crítico, transmiten sentido y operan en la memoria social y política del territorio, construyendo otros relatos posibles sobre el vínculo entre los individuos y su entorno.

Ignacio Rodríguez desde su artículo "Simular el Territorio" propone pensar el territorio desde el simulacro. Para ello presenta el proyecto Bienvenidos-como disparador desde un abordaje artístico, no lineal y extra académico-para pensar el territorio como una forma más de producción subjetiva relacionada a prácticas de consumo y segmentación social, y para visibilizar las tensiones vinculadas a los espacios públicos de la ciudad de Punta del Este. Parte de la base de que el espacio público es un espacio de disputa, donde ocurren dinámicas y tensiones en diferentes niveles. Bienvenidos propone observar la reacción y el posicionamiento ético de la comunidad ante la presencia no planificada de dispositivos que cuestionan la propiedad, los bienes raíces y la retórica publicitaria, entre otras cuestiones que suceden en ciudades donde la especulación inmobiliaria y el turismo tienen un rol protagónico.

Por último, el artículo de Victoria Lembo "La ciudad de Punta del Este entre dos cortos y dos novelas: análisis de las representaciones urbanas desde la promoción turística, el audiovisual y la literatura" propone la reflexión de diferentes construcciones discursivas provenientes de la promoción turística, del arte y de la literatura y, a partir de ellas, busca identificar y caracterizar alguna de las representaciones existentes sobre la ciudad balnearia de Punta del Este, especialmente aquellas que refieren al espacio urbano, el entorno natural y las relaciones humanas entabladas entre los habitantes, los turistas y el territorio. A través del análisis plantea identificar el discurso hegemónico sobre la ciudad y aquellos otros discursos que quedan más al margen en los procesos de enunciación 
para lograr comprender las distintas ciudades que conforman el espacio urbano y de esta manera, enriquecer las variantes de la complejidad urbana que las perspectivas reduccionistas de otros discursos omiten.

En esta misma línea se encuentra el ensayo de Marcos Castaings, "La ficción, el relato y la construcción mítica del paisaje como herramientas activas de producción territorial", que si bien no trata de la conurbación Maldonado-Punta del Este en particular, busca reflexionar sobre el territorio proponiendo la fundación de una nueva mirada que se aparte del clásico planteo con acento tecnificista propio de algunas disciplinas como la arquitectura. Su propuesta consiste en privilegiar las herramientas creativas sobre las diagnósticas y en postular como base la construcción ficcional, la utilización del paisaje (entendido de manera compleja) como tejido conectivo del territorio (en lo social, cultural, estético, productivo, económico, ético, etc.) y el relato (storytelling) como herramienta fundamental y vehículo generador de posibles futuros, verosímiles y compartidos.

Por último, Jimena Marrero et al, en su artículo "Ecocrítica y resistencia pedagógica: formación docente y contextos de encierro", buscan reflexionar sobre la experiencia resultante del trabajo con centros educativos y la sociedad, enmarcada en la metodología extensionista crítica y con el fin de generar una relación dialógica entre los mismos, produciendo conocimientos en función de necesidades sociales que partan de la interacción entre los saberes científicos y los saberes populares. En concreto, las autoras reflexionan sobre lo educativo desde aquellos elementos que promueven los saberes comunitarios, como ser la bioconstrucción, la huerta orgánica y la alimentación desde la olla popular en contextos de encierro.

Los artículos en la segunda sección le echan un segundo vistazo a figuras canónicas como Charles Darwin, Von Humboldt, Linnaeus, Francis Bacon, que han influido en el interés de emprender una revaluación de epistemologías y representaciones hegemónicas o dominantes. Dichas contribuciones ofrecen relecturas de textos y procesos culturales históricos para tratar de rescatar aspectos y elementos de visiones alternativas que han sido relegadas a los márgenes en la marcha de la modernización en Latinoamérica.

En su artículo denominado "La figuración del paisaje de Cholula a través de la mirada de Alexander von Humboldt: reflexiones sobre su transformación territorial y sociocultural", Melissa Schumacher y Anne K. Kurjenoja argumentan que Humboldt fue pionero en integrar la geobotánica como una herramienta de análisis visual y paisajístico, entendiendo la unidad de la naturaleza como un "todo" con diferentes escalas y planos de análisis. Las autoras utilizan elementos del Naturgemälde de Humboldt y los Sistemas Socio-ecológicos del Paisaje para describir la transformación física que ha tenido el paisaje ru-urbano de Cholula, México, presentando un análisis gráfico de diferentes tejidos que yuxtaponen el territorio mencionado.

Paula Lopez Wood, en su artículo "Lautaro Edén Wellington: viaje de retorno a las 'zonas de contacto' de la Patagonia occidental” propone analizar, a partir de la historia del joven kawésqar enviado desde Patagonia occidental para 
formarse como militar en Santiago de Chile en la década de 1940, las formas discursivas que han representado el viaje de retorno de Lautaro a su comunidad y su posterior fuga a los canales del archipiélago magallánico. En el artículo indaga en la posibilidad de dar con una versión de la historia de Lautaro que presente una subjetividad del indígena canoero con agencia y voluntad propia, para ofrecer alternativas a los discursos de dominación presentes en los textos analizados que han representado dicho relato.

En "Antártida: Infierno blanco. Una aproximación desde la literatura", Sebastián Astorga adopta un enfoque comparativo para analizar cinco textos en los cuales el viaje hacia la Antártida se imagina como una catábasis (viaje a un infierno), a la vez que una provocación (hybris) al orden universal. La lectura de las obras planteadas-cuatro clásicas de la literatura anlglófona de finales del siglo XVIII a las primeras décadas del siglo XX, y una novela chilena de 1945-muestra repeticiones estructurales y simbólicas que dan cuenta de una clave crítica: la potencia de la naturaleza salvaje sobre el registro humano y la catástrofe en que puede desembocar el ánimo de conquista y dominio.

Leandro Delgado, en "Modernidad y anarquía: sobre lo colectivo en las crónicas de Rafael Barrett", presenta las reflexiones del cronista anarquista y modernista español-paraguayo Rafael Barrett (1876-1910) con el objetivo de señalar elementos de un pensamiento ambiental presentes en su proyecto moderno. El artículo propone un diálogo con la noción de "lo colectivo" de Bruno Latour, revelando dos lecturas de la obra de Barrett que pueden ser consideradas contradictorias: al mismo tiempo que considera un mundo compartido por seres humanos y no humanos, ubica al ser humano en una posición jerárquica que lo habilita a tomar decisiones sobre el resto de los seres vivos. De última, Delgado propone una noción anarquista de individuación que trasciende la contradicción y que afirma este lugar jerárquico para alcanzar, justamente, la integración con la naturaleza.

Mac Wilson, en "Historia no natural: Human Subjectivity and "Nature" in Alfredo Veiravé's Historia Natural" reflexiona sobre una constante en el desarrollo de la voz poética del argentino Alfredo Veiravé (1928-1991), específicamente, una preocupación con la forma dualista que las ciencias y las humanidades ven el mundo natural y el mundo artificial. Según el autor, Veiravé con su poesía proporciona un ejemplo fundamental del giro posambiental en el pensamiento ecológico latinoamericano, a su vez reconociendo y problematizando el papel de la subjetividad humana en el destino de los entornos, paisajes y territorios.

Juan Aguerre, en su artículo "Labrando la Tierra Prometida: estudio de las representaciones de la naturaleza y el espacio en Los gauchos judíos de Alberto Gerchunoff", propone un estudio de las distintas representaciones de la naturaleza, del mundo vegetal en particular, y del espacio en la novela Los gauchos judíos (1910) de Alberto Gerchunoff. El autor lo analiza desde la convergencia entre la ecocrítica con los estudios del "giro espacial" en las humanidades. Adoptando una postura crítica, con un pie en la literatura y otro en la tierra, esta perspectiva aclara una negociación entre lo humano y lo no-humano en la novela. 
Maria Eugenia Rasic, en "Arte y poesía en Cura Malal: un corral de piedras donde el paisaje y la comunidad resisten", analiza a través del arte y la poesía impulsadas por un proyecto colectivo actual en Cura Malal (provincia de Buenos Aires), los procesos de modernización y de transformación histórica ocurridos en la comunidad y en el paisaje rural-serrano. Por otro lado, reflexiona sobre los procesos de recuperación y de preservación de un sentido de comunidad y de paisaje que dichas transformaciones históricas han dejado como ruinas pero que, al mismo tiempo, han emergido como fuerzas latentes. En este sentido, el arte y la poesía son acciones individuales y colectivas capaces de visibilizar y hacer sonar esas supervivencias, así como también resguardar a la comunidad de Cura Malal y a su entorno natural de la desaparición.

Los trabajos en la tercera sección del número se enfocan en textos contemporáneos que reflejan las ansiedades particulares de las primeras décadas del siglo XXI. Los primeros tres artículos toman como objeto de análisis relatos audiovisuales, dando cuenta de cómo la forma del relato, y las técnicas particulares del cine, ayudan, simultáneamente, a reproducir y problematizar las ansiedades culturales latentes sobre cuestiones de territorio y ambiente.

En "Escenarios del descubrimiento extraterrestre: los discursos de la ciencia de la conquista en ficciones audiovisuales recientes", Cristian Foerster analiza desde la perspectiva de las humanidades (la historia de la ciencia particularmente) las tensiones narrativas que envuelven al escenario fundacional sobre el que se articula la empresa de colonización de Marte, tomando como corpus de análisis la serie Mars (2016) del National Geographic Channel. Por un lado, reflexiona sobre cómo, a través de la administración de la idea de fascinación, la ciencia y los científicos se transforman en los protagonistas en el escenario del descubrimiento y conquista de nuevos territorios. Simultáneamente, analiza los conflictos que supone la conquista marciana en una genealogía que la emparenta con las figuraciones de los viajes antárticos de la primera modernidad y la colonización de América.

Rodrigo Bacigalupe reflexiona sobre la relación entre la geopoética y el mundo natural, identificando un funcionamiento "vegetal" en la relación entre el cine y la literatura en su artículo "La Flor (2018) de Mariano Llinás: autopoeisis y paisajes metaliterarios, una película que crece en el sur". A través de la recursividad poética en clave borgeana, el autor analiza cómo el director del film logra dotar al compendio de casi catorce horas de duración de una forma de individualidad que no se deja definir por los cánones tradicionales del término individuo. Por medio de la mereología-estudio de las relaciones entre partes dispares-demuestra una configuración de las representaciones imaginarias de la Patagonia en la que los ecosistemas se tornan representativos de una realidad que trasciende la geografía.

En "La tierra y la sombra: cine háptico, violencia ambiental y desplazamiento forzado en Colombia", Carolina Sanchez muestra como la película La tierra y la sombra (2015) del director colombiano César Acevedo representa las causas y consecuencias del desplazamiento forzado por los territorios ecológicos a través de la historia de una familia que se niega a abandonar su tierra por la imposición del monocultivo de caña de azúcar. La autora sugiere que, a través de 
técnicas de cine háptico que usan la visión como un sentido del tacto- la película hace a los espectadores experimentar los efectos de lo que Rob Nixon (2011) llama la "violencia lenta", de alguna manera convirtiendo al espectador en un testigo de este tipo de violencia.

Los artículos agrupados en la segunda parte de esta última sección ofrecen un diagnóstico de la condición del Antropoceno en clave negativa. Sin embargo, lejos de quedar atascado en el pensamiento apocalíptico, el análisis que ofrecen de una variedad de textos contemporáneos latinoamericanos invita a una revaloración del potencial radical de figuras como la toxicidad, la extinción, el apocalipsis, el "hedor" y el "mal vivir", dado que apuntan hacia la necesidad de ponerle fin a modos destructivos de habitar el mundo. Estas contribuciones sugieren que una revaloración del pensamiento negativo potencialmente puede abrir caminos hacia la imaginación de otros mundos posibles.

Para este número de Tekoporá tenemos el agrado de contar con un artículo original de una de las principales referentes de la ecocrítica trabajando en el campo de literatura latinoamericana. Gisela Heffes demuestra que sigue identificando nuevas corrientes a la vanguardia de las "constelaciones" (Heffes, 2014, p. 32) de la ecocrítica. En "Escrituras tóxicas: cuerpos y paisajes alterados", se enfoca en el reciente giro rural que ha dado la producción literaria argentina contemporánea. Heffes remite a la noción de discurso tóxico propuesta por Laurence Buell (1988) para analizar textos de Samantha Schweblin (2014), Juan Diego Incardona (2016), y Julián Joven, seudónimo de Cristian Molina (2016). En estas narrativas "agro-tóxicas", el cultivo de la soja transgénica metamorfosea el espacio del campo en un paisaje contaminado y contaminante, inoculando indiferenciadamente cuerpos humanos y no humanos. La representación tanto corporal como espacial se lee como una textualización que rediseña la relación entre sujeto y entorno natural el campo desplazando un discurso del "buen vivir" por una escritura de lo que Heffes propone como del "mal vivir".

Notando como la figura del niño funciona como significante del futuro en "ficción climática" proveniente del hemisferio norte, en "La reproducción más allá de la extinción: cuidados desintoxificados en ficciones antropocénicas latinoamericanas" Allison Mackey ofrece una lectura del cuento "Abel" (Anacristina Rossi, Costa Rica, 2013) y la novela Distancia de Rescate (Samantha Schweblin, Argentina, 2014) a través de teorías feministas y de la ecocrítica materialista. Según la autora, estas narrativas especulativas abarcan las implicaciones negativas de la reproducción sin generación, desafiando, reflexionando y perpetuando ansiedades en torno a las relaciones de cuerpo y la diferencia sexual. Como ejercicio de la imaginación, contemplar la extinción humana nos invita a preguntar: ¿qué otras formas de vida podrían evolucionar a partir, o en lugar de la "humanidad" tal como la conocemos?

En "Ecologías queer caribeñas y capitalismo del desastre en La mucama de Omicunlé (2015) de Rita Indiana Hernández", Sebastian Figueroa y Lina Martínez analizan la novela especulativa de la escritora dominicana Rita Indiana desde la perspectiva de las ecologías queer. Este enfoque busca desestabilizar nociones normativas de la sexualidad y la naturaleza a partir de discursos y prácticas que 
articulan las relaciones entre cuerpos humanos y no humanos desde una posición fundamentalmente no evolutiva, no reproductiva y multi especista. El análisis propuesto sobre La mucama de Omicunlé ofrece una oportunidad única para explorar este enfoque al presentar una trama de conspiración eco-política-en la que intervienen personajes transgéneros, rituales afrocaribeños, animales mágicos y viajes en el tiempo-con el fin de salvar el Mar Caribe de un desastre químico.

En "Umbrales del hedor: diálogos ecocríticos entre la poesía de Teresa Orbegoso y la filosofía americanista de Rodolfo Kusch", Azucena Castro lee la obra de la poeta Teresa Orbegoso (Lima, 1976-) a través de la filosofía americanista de Rodolfo Kusch. Focalizándose en Orbegoso, busca identificar cómo esa poesía contemporánea activa la noción kuscheana de "hedor del suelo" inspirada en los saberes ancestrales aimara y quechua del norte argentino, del sur de Bolivia y de pueblos de Perú, para poner de relieve un acercamiento poético-filosófico al suelo. Además, sitúa la filosofía americanista de Kusch en las discusiones ecocríticas contemporáneas y propone recuperar un vocabulario crítico de la filosofía de Kusch para entender las elaboraciones de esta poesía contemporánea que se aproxima a nociones del suelo desde lo ancestral, lo corpóreo y lo precario haciendo uso de una episteme filosófica latinoamericana.

Por último, seríamos negligentes si no reconociéramos el rol de la experiencia que nos unió en el proceso de realización de este número a pesar de las distancias geográficas entre editores/as y autores/as: la pandemia del COVID-19 ha alarmado ya no sólo a la comunidad científica sino a la humanidad en su conjunto, sacudiendo los cimientos ilusorios del excepcionalismo humano, y demostrando, de manera implacable, la porosidad y vulnerabilidad de nuestros cuerpos ubicados dentro del mundo material. Reconocer a estos procesos "trans-corporeales"

nos permite reimaginar la corporeidad humana, y la materialidad misma, no como una sustancia utópica o romántica existente antes de la inscripción social, sino como algo que siempre lleva el rastro de la historia, la posición social, la región y la distribución desigual del riesgo. (Alaimo, 2010, p. 261)

Las implicancias de este fenómeno a largo plazo aún no son claras, pero basta con ver las actuales consecuencias económicas, políticas y sociales para reflexionar sobre crisis futuras asociadas al cambio climático o a los sistemas socioecológicos. A pesar de que desde las humanidades podamos percibir que vivimos en tiempos interesantes, los estertores de estas crisis aún no han comenzado a pronunciarse en su totalidad. Por eso hemos decidido cerrar esta introducción con las palabras de la poeta chilena Elvira Hernández (2018, p. 9):

\section{Aves de paso}

Sí. Eso somos.

Pero nos hemos acostumbrado

A comportarnos como monumentos.

Y así nos va. 


\section{Referencias}

Alaimo, S. (2010) Bodily Natures: Science, Environment, and the Material Self. Bloomington, IN: Indiana University Press.

Barad, K. (2007). Meeting the Universe Halfway: Quantum Physics and the Entanglement of Matter and Meaning. Durham: Duke University Press.

Baudelaire, C. (1996) Salones y otros escritos sobre arte. Madrid: Visor.

Braidotti, R. (2019) Posthuman Knowledge. Cambridge: Polity Press.

Boling, B. (2006) "The Trope of Nature in Latin American Literature" Studies in 20th \& 21st Century Literature. Volume 30, Issue 2.

Buell, L. (1998). “Toxic Discourse” Critical Inquiry, 24 (3): pp. 639-665.

Buell, L. (2005) The Future of Environmental Criticism. Wiley, Blackwell.

Carson, R. (1962) Silent Spring. Boston: Houghton Mifflin.

Davis, H. y Todd, Z. (2017) "On the Importance of a Date, or Decolonizing the Anthropocene" ACME: An International Journal for Critical Geographies 16 (4), pp. 761-780.

DeLoughrey, E. (2015) "Ordinary Futures: Interspecies Worldings in the Anthropocene" en Global Ecologies and the Environmental Humanities: Postcolonial Approaches, pp. 352-372, editado por Elizabeth DeLoughrey, Jill Didur, and Anthony Carrigan. New York y London: Routledge.

Flys Junquera, C.; Marrero Henríquez, J.M.; y Barella Vigal, J. (eds). (2010) Ecocríticas: Literatura y medio ambiente. Madrid: Iberoamericana-Vervuert.

Giunta, A. (2014). ¿Cuándo empieza el arte contemporáneo? Buenos Aires, Argentina: Fundación arte BA.

Heffes, G. (2014) "Introducción: Para una ecocrìtica latinoamericana: entre la postulación de un ecocentrismo crítico y la crítica a un antropocentrismo hegemónico" Revista de Crítica Literaria LatinoamericanaAño XL, № 79. Lima-Boston: pp. 11-34

Hernández, Elvira (2018). Pájaros desde mi ventana. Santiago: Alquimia Ediciones.

Iovino, S. y Oppermann, S. (Eds.) (2014). Material Ecocriticism. Bloomington: Indiana University Press. 
Evia, G. (2006) “Por qué Teko-Ha?” Red de Ecología Social CLAES. Recuperado de: https://ecologiasocial.com/2006/06/por-que-teko-ha/

Glotfelty, C. (1996) "Introduction: Literary Studies in an Age of Environmental Crisis" en The Ecocriticism Reader: Landmarks in Literary Ecology, pp. xv-xxxvii, editado por Cheryl Glotfelty y Harold Fromm. Athens, U.S.A: University of Georgia Press.

Lefebvre, H (2013) La producción del espacio. Capitan Swing, Madrid.

Lewis, S. y Maslin, M. (2015) "Defining the Anthropocene" Nature 519, pp. 171-180. Recuperado de: https://doi.org/10.1038/nature14258

Steffen, W. et al. (2015) "The trajectory of the Anthropocene: The Great Acceleration" The Anthropocene Review 2.1: pp. 81-98.

Whyte, K.P. (2016) "Is it Colonial Déjà Vu? Indigenous Peoples and Climate Injustice" En Humanities for the Environment: Integrating Knowledges, Forging New Constellations of Practice, pp. 88-104, editado por Joni Adamson, Michael Davis, y Hsinya Huang. London, UK: Earthscan Publications. 